\title{
MEDICAID EXPANSIONS AND WELFARE CONTRACTIONS: OFFSETTING EFFECTS ON PRENATAL CARE AND INFANT HEALTH?
}

\author{
Janet Currie \\ Jeffrey Grogger \\ Working Paper 7667 \\ http://www.nber.org/papers/w7667 \\ NATIONAL BUREAU OF ECONOMIC RESEARCH \\ 1050 Massachusetts Avenue \\ Cambridge, MA 02138 \\ April 2000
}

\begin{abstract}
We would like to thank Aaron Yelowitz for helpful discussions about the administrative data. Bruce Meyer, and seminar participants at the University of Chicago, Northwestern, UC San Diego, UC Davis, Texas A\&M, the NBER Summer Institute and RAND made valuable comments. Currie gratefully acknowledges support from the Canadian Institute for Advanced Research, and the National Institute of Child Health and Human Development under contract \#R01-HD3101A2. The authors are solely responsible for any errors. The views expressed herein are those of the authors and are not necessarily those of the National Bureau of Economic Research.
\end{abstract}

(C) 2000 by Janet Currie and Jeffrey Grogger. All rights reserved. Short sections of text, not to exceed two paragraphs, may be quoted without explicit permission provided that full credit, including $(\mathrm{C}$ notice, is given to the source. 
Medicaid Expansions and Welfare Contractions: Offsetting Effects

on Prenatal Care and Infant Health?

Janet Currie and Jeffrey Grogger

NBER Working Paper No. 7667

April 2000

JEL No. I18, I38

\begin{abstract}
$\underline{\text { ABSTRACT }}$
Evaluations of changes to the Medicaid program have focused on increases in the generosity of income cutoffs for Medicaid eligibility. Previous research shows that despite dramatic increases in the number of births paid for by the Medicaid program, women often enroll in Medicaid at the point of birth rather than before. States have addressed this problem by adopting administrative measures designed to simplify the Medicaid application process and encourage the use of prenatal care. At the same time, recent declines in welfare caseloads may effectively increasing administrative barriers to obtaining care.

We examine the effects of these three types of policies (changes in income eligibility, administrative reforms, and changes in welfare caseloads) on the use of prenatal care and infant health using data from birth certificates covering all U.S. births between 1990 and 1996. We find that increases in income cutoffs increased the use of prenatal care, while decreases in welfare caseloads reduced the use of prenatal care, especially among blacks. The administrative reforms we consider had little effect. The changes in the utilization of prenatal care that were induced by increases in income eligibility cutoffs and decreases in welfare rates led to small but statistically significant reductions in the incidence of very low birthweight among whites.
\end{abstract}

Janet Currie

Department of Economics, UCLA

405 Hilgard Avenue

Los Angeles, CA 90095-1477

and NBER

currie@simba.sscnet.ucla.edu
Jeffrey Grogger

Department of Policy Studies, UCLA

405 Hilgard Avenue

Los Angeles, CA 90095-1477

and NBER

jgrogger@ucla.edu 
Medicaid, a public insurance program that largely serves poor women and children, has undergone extensive changes since the mid-1980s. An important goal of these changes is to improve infant health by encouraging pregnant women to obtain adequate prenatal care. To the extent that prenatal care improves birth outcomes (Institute of Medicine, 1985), policies that encourage the use of prenatal care will reduce infant mortality, which remains high in the U.S. compared to other developed countries.

Previous research evaluating changes to the Medicaid program has focused on increases in the generosity of the income cutoffs for Medicaid eligibility (c.f. Currie and Gruber, 1996). Although these eligibility expansions have increased the fraction of births paid for by Medicaid from 15 to nearly 40 percent (National Governor's Association, 1997), many women still fail to obtain adequate prenatal care, enrolling in Medicaid at the point of birth rather than before. This pattern of delayed enrollments may mean that Medicaid ends up sponsoring expensive treatment for gravely ill infants, rather than preventing their illnesses through appropriate prenatal care.

In order to address this problem, states have adopted a variety of administrative measures to reduce non-price barriers to care. The objective of these policies is to encourage the use of prenatal care by simplifying the Medicaid application process for pregnant women. Common reforms include: presuming that pregnant women were eligible for Medicaid while their applications were being processed and/or expediting the processing of applications for pregnant women; dramatically shortening and simplifying application forms; and eliminating the requirement for face-to-face interviews by allowing mail-in applications from pregnant women.

At the same time, many states experienced sharp declines in their welfare caseloads; the welfare rolls have fallen by 44 percent since 1993, at least in part because of recent welfare reforms (Administration for Children and Families, 1999; Council of Economic Advisers, 1994; Grogger and Michalopoulos, 1999; Moffitt, 1999). These declines had potentially important negative impacts on Medicaid coverage because many poor women obtained Medicaid coverage "automatically" when they 
enrolled in the Aid to Families with Dependent Children (AFDC) program. Thus, the loss of AFDC effectively raised the administrative bar for women seeking Medicaid coverage, by requiring them to go through a separate and unfamiliar application process (Ellwood and Kenney, 1995).

This paper compares the effects of these changes in the policy environment on the utilization of prenatal care. We also examine the effect of the increases in prenatal care that were induced by these policies on birthweight, an important indicator of infant health. In order to conduct these analyses, we merge information about income cutoffs, administrative reforms, and welfare caseloads with the Vital Statistics Detail Natality files for 1990 to 1996 , which contain information about virtually every birth that occurred in the United States over this period. The available literature suggests that the effects of the policies we examine may vary with race and socio-economic status. Thus, we conduct separate analyses of the effects of the administrative reforms by race as well as for disadvantaged mothers (teens and high school dropouts).

We find that higher income cutoffs and higher welfare caseloads encouraged the utilization of prenatal care, while the administrative reforms did not. Reduced form estimates of the effects of these policy variables on birth weight indicate that higher income cutoffs reduced the risk of very low birthweight among whites, while higher welfare caseloads reduced the incidence of both very low birthweight and low birthweight among blacks. Finally, we estimate two stage least squares (TSLS) models in which the policy variables serve as instruments for measures of the adequacy of prenatal care. Given the controversy about the effects of prenatal care, these models which are identified using exogenous variation in policy as instruments are of independent interest. Our TSLS estimates suggest that the increases in the use of prenatal care that were induced by changes to the Medicaid program led to small reductions in the incidence of very low birthweight (though not low birthweight) among whites. Among blacks our estimates suggest that welfare rates have independent effects on birthweight independent of any effects they have on use of prenatal care, and that reductions in the use of prenatal 
care associated with declines in welfare caseloads had little impact on birthweights.

\section{Background}

\subsection{Changes to the Medicaid Program and to Welfare}

Eligibility for the Medicaid program used to be largely restricted to participants in AFDC, which meant that income cutoffs were very low. Beginning in the late 1980s, Congress enacted several laws breaking the link between welfare and Medicaid eligibility. By April 1990, states were required by federal law to provide Medicaid coverage to pregnant women with incomes up to $133 \%$ of the poverty level, and states had the option of receiving federal matching funds to cover women with incomes up to $185 \%$ of the poverty level.

Studies of the first years of these expansions of the income cutoffs show that many newly eligible, uninsured, pregnant women did not take up coverage in time to benefit from improved prenatal care. For example, Currie and Gruber (1996) suggest that as many as half of these women did not take up coverage in time. Moreover, non-participation was concentrated among women who were not income-eligible for AFDC, suggesting that simply increasing the income eligibility cutoff did not break the link between welfare receipt and Medicaid coverage.

In response, state governments have adopted a range of administrative reforms designed to make it easier for pregnant women to enroll, irrespective of their welfare status. Table 1 shows the number of states that had adopted these measures in each half year between 1990 and $1996 .^{1}$ The source for these

1 In addition to the measures shown in Table 1, many states also adopted two other measures. One was to eliminate "asset tests" for Medicaid eligibility, meaning that applicants no longer had to document the value of assets such as cars and life insurance policies. The second was to "outstation" eligibility workers in places other than welfare offices, such as hospitals serving poor people. While we believe that these measures are of potentially great importance, they show little variation over our sample period. Most states had dropped asset tests by 1990, and all 
data is the National Governor's Association's (NGA) Maternal and Child Health newsletters, which began to publish information regarding the administrative reforms in 1990. Information about income eligibility cutoffs has been published by the NGA for a longer period. The table shows that the law often changes in mid-year. Hence, we merge the NGA data to the Vital Statistics data by half year rather than years. Finally, Table 2 indicates that many states have continued to raise the income eligibility thresholds for pregnant women beyond the $133 \%$ of the federal poverty line that is currently required by federal law.

At the same time that Medicaid eligibility for pregnant women was expanding, a number of states were reforming their welfare systems under waivers from the Aid to Families with Dependent Children (AFDC) program. These welfare reform efforts culminated in the passage of the federal Personal Responsibility and Work Opportunity Reconciliation Act (PRWORA) of 1996, which required states to replace AFDC with the new Temporary Assistance for Needy Families Program by July 1997. If the administrative reforms to the Medicaid program were successful in breaking down barriers to Medicaid access, then we would not expect changes in the welfare roles to have any effect on the use of prenatal care among Medicaid-eligible pregnant women. The reason is that the women remain eligible for Medicaid coverage in the event of pregnancy whether or not they are welfare recipients. However, if administrative barriers to accessing the program remain important, then we might expect the welfare reforms to have the unintended consequence of reducing access to prenatal care under the Medicaid program. Hence, other things being equal, the effect of the welfare rate on the utilization of prenatal care provides a test of the importance of administrative barriers to accessing the Medicaid program.

The annual state-level data on welfare caseloads that we analyze comes from the U.S. Department of Health and Human Services (various years); we divide the number of recipients by the state population in order to obtain a welfare utilization rate. Over our sample period the mean utilization rate was 4.5

\footnotetext{
states began outstationing eligibility workers (by federal mandate) in 1991. Hence, we do not attempt to evaluate the effectiveness of these measures here.
} 
percent, but it varied greatly between states and within states over time (Blank, 1997; Wallace and Blank, 1999). For example, the utilization rate in Massachusetts rose from 4.4 percent in 1990 to 5.4 percent in 1993, falling to 3.9 percent by 1996. In Califomia, it rose from 6.4 percent in 1990 to 8.5 in 1995 , and stood at 8.3 percent in 1996 . Welfare rates are shown for selected state and years in Table 2.

These welfare rates may reflect business cycle effects as well as access to the Medicaid program via welfare. Hence, in the models we estimate, we will also control for state unemployment rates. Annual state-level unemployment data come from the Bureau of Labor Statistics' Local Area Unemployment Statistics program.

\subsection{Non-Monetary Barriers to Care}

The fact that many people eligible for social programs do not participate in them suggests that income eligibility is not the only barrier to care. For example, Blank and Ruggles (1996) find that only two-thirds of those eligible for AFDC and Food Stamps participate. Blank and Card (1991) find similar results for participation in the Unemployment Insurance program. Economists have focused on two explanations for eligible non-participation: "welfare stigma" (c.f. Moffitt, 1983) and transactions costs associated with enrollment in the program. For example, Blank and Ruggles find that those with short

expected welfare stays are the least likely to enroll, presumably because the expected benefits of enrollment do not outweigh the costs of applying. The rates of non-participation in Medicaid are even higher than those of non-participation in other programs, which suggests that barriers to obtaining medical care under this program may be especially great.

Pregnant women who are not automatically eligible for Medicaid due to participation in welfare must go through a separate application process. They may be required to show birth certificates and/or citizenship papers, rent receipts and utility bills to prove residency, and pay stubs as proff of income. Many states have a time limit on the number of days the applicant can take to provide documentation--for 
example, Georgia gives 10 working days. Applicants are often required to return for several interviews. The available evidence suggests that up to a quarter of Medicaid applications are denied because applicants do not fulfill these administrative requirements: They cannot produce the necessary documentation within the required time or fail to attend all of the required interviews (GAO, 1994).

While it may be quite difficult for individuals to overcome these barriers, hospitals have both the incentive (since they must provide care to women in labor), and the means to do so (Saywell, 1989). Many hospitals have established Medicaid enrollment offices on site. These offices assist people in completing applications and tell them how to obtain necessary documentation (GAO, 1994). Hospitals in at least 32 states and the District of Columbia also employ private firms to help them enroll eligible patients in the Medicaid program. Thus, it is not surprising that many births are covered by Medicaid even when prenatal care is not.

Even those who are covered by Medicaid may have difficulty obtaining preventive care, since Medicaid typically pays about half of what private health insurance would pay. One study of new mothers who had arrived in emergency rooms to deliver with "no physician of record" found that 64 percent of the women cited their inability to find a doctor willing to accept them as the largest barrier to obtaining prenatal care (Aved et al., 1993). These problems may be even more severe for minority mothers. American cities are highly segregated by race and income (Massey and Denton, 1993). Urban blacks often live in parts of the city that are shunned by physicians in private practice and hence are more likely to be served by large urban teaching hospitals (Fossett et al., 1992).

Finally, we ask whether responses to administrative reforms vary by socioeconomic status, where lower socioeconomic status is proxied using teen motherhood and/or less than a high school education. While it may seem that barriers such as lengthy application forms would prove most daunting to the most disadvantaged women, it is also possible that these women face other barriers that are likely to reduce the effectiveness of the administrative reforms. For example, some poor mothers do not use the prenatal care 
that is available to them. One study of low-income women in New York City found that the two most commonly cited reasons for failing to obtain adequate prenatal care were not lack of insurance coverage, but "feeling depressed and not up to going for care" and "needing time and energy to deal with other problems" (Brown, 1989).

In summary, the literature suggests that there are many non-monetary barriers to accessing the Medicaid program. Moreover, the importance of these barriers may vary with the characteristics of the potential patients. The administrative reforms that have been implemented by the states address some, but by no means all, of these problems. Thus, the extent to which they will be successful in increasing participation must be assessed empirically. If the administrative reforms have not been successful in easing access to Medicaid among those who are not on welfare, then the declines in the welfare caseloads that have accompanied welfare reform can be expected to have affected the utilization of prenatal care among Medicaid eligible pregnant women.

\subsection{The Importance of Prenatal Care}

As discussed above, the goal of recent changes to the Medicaid program for pregnant women is to improve infant health by encouraging the use of prenatal care. There are a number of ways that prenatal care could improve infant health. First, prematurity is the biggest factor contributing to low birthweight. Creasy et al. (1980) found that over $60 \%$ of women who went on to deliver preterm births could have been identified using inexpensive ( $\$ 10$ to $\$ 20$ ) screenings in the first prenatal care visit. Several clinical studies cited in the Institute of Medicine (1985) suggest that providing appropriate prenatal care to women identified by these screenings (at a cost of $\$ 400$ to $\$ 500$ per woman) could reduce the incidence of low birthweight among these women by more than $20 \%$. The clinical evidence suggests that prenatal care may become even more important as the causes of premature birth (such as maternal infection (c.f. Fiscella, 1996) and hormones related to stress levels (Smith, 1999)) are better understood. 
As has been noted by a number of economists, however, comparisons of outcomes among women who do and do not receive prenatal care are likely to be biased by self-selection: Women who do not obtain proper prenatal care may be more likely to bear unhealthy children for other reasons (c.f. Harris, 1982). Compared to clinical studies, studies based on survey data that attempt to control for this selection typically find little effect of prenatal care on birthweight (c.f. Rosenzweig and Schultz, 1982, 1983, 1988; Frank et al., 1991; Corman et al., 1997).

This contrast between clinical and survey-based studies suggests that while prenatal care may be of great value to some high-risk women, other women may not benefit from prenatal care. Alternatively, these different findings may reflect the fact that clinical studies focus on the gains that could be attained under ideal circumstances, whereas surveys reflect the impact of prenatal care as it is practiced in the field-typically little information is available about the quality rather than the quantity of care. A third possibility is that many of the earlier studies have been forced to rely on questionable identification assumptions. For example, it may be assumed that maternal education affects use of prenatal care but has no independent effect on birth outcomes.

This study will improve on past work that has estimated examined the effects of prenatal care in the general population by taking advantage of the fact that there have been exogenous changes in the policy environment which can reasonably be assumed to have affected birth outcomes only through their effects on the use of prenatal care. These policy variables will be used as instruments in TSLS models of the effects of prenatal care on birthweight which are estimated below.

\subsection{Measures of Prenatal Care}

We use three common measures of prenatal care which can be constructed from information available on the birth certificate. The first is whether care began after the first trimester. Timeliness is an important element of prenatal care adequacy. The first visit is used to establish baselines for such 
things as maternal weight and blood pressure which can then be used to track the progress of the pregnancy. The second measure is whether the mother went without prenatal care. Relatively few women report that they received no prenatal care at all, but if prenatal care has diminishing marginal effectiveness, we may be particularly concerned about this group. The third measure is whether the mother received inadequaqte prenatal care where adequacy is assessed by taking into account when prenatal care began, and the total number of visits conditional on the length of the pregnancy. This measure is constructed by the National Center for Health Statistics and appears on the Vital Statistics Detailed Natality files. In principle, it is a better measure than whether the care began in the first trimester. However, it may be measured with more error.

\subsection{Birthweight as a Measure of Infant Health}

We focus on birthweight as the key indicator of the underlying health of newborns. Many previous analyses have focused on low birthweight, which is defined as birthweight less than 2500 grams, about 5.5 pounds. In 1987, the Office of Technology Asessment (OTA, 1987a) found that children of low birthweight were at high risk of neonatal mortality and experienced post-neonatal mortality rates 10 to 15 times greater than those found among infants of higher birthweight. Low birthweight survivors were also at higher risk of handicaps such as cerebral palsy, seizure disorders, blindness, deafness and learning disorders (McCormick et al., 1992; OTA, 1987b, Chaikind and Corman, 1990).

Typically, medical problems are more severe for the lightest infants. For example, Horbar et al. (1993) found that in a sample of very low birthweight children (usually defined as birthweight less than 1500 grams), each increase in birthweight of 100 grams was associated with a decrease of approximately $10 \%$ in the probability of death, other things being equal. Moreover, recent improvements in medical technology have pushed the critical birthweight, at which infants are at high risk of death and impairment, lower and lower (Cutler and Meara, 1999). Thus, in addition to examining the incidence of low 
birthweight, we also examine the incidence of very low birthweight.

A potential problem is that birth certificates are only completed for infants who are bom alive. The sample of pregnancies that result in live births may be affected by changes to the Medicaid program. Suppose, for example, that as a result of access to Medicaid, a pregnancy that would have ended in stillbirth results in a live birth. Then the Medicaid expansions will have changed the sample of live births. Moreover, the child who would have been stillborn but survived may still be very unhealthy. In this case increases in survival probabilities for the most at-risk fetuses could make it appear that Medicaid access was associated with poorer birth outcomes. In principle, fetal selection could even lead to "wrong-signed" coefficients on the variables of interest.

We address fetal selection by merging information on fetal deaths that occurred after 20 weeks of gestation with the sample of live births and repeating our analysis on this larger sample of pregnancies that lasted at least 20 weeks. We focus on fetal deaths after 20 weeks because all states require reporting of fetal deaths that occur after 20 weeks. In contrast, requirements for the reporting of fetal deaths vary across states, and many fetal losses in the early weeks of pregnancy may go undetected by even the pregnant women themselves. Since fetuses less than 20 weeks are not viable, this enlarged sample is likely to include all of the pregnancies in which the application of medical technology at the time of the birth resulted in a live birth rather than a still birth. Thus, by using the enlarged sample, we can rule out the possibility than the effects of our Medicaid policy variables are due to fetal selection stemming from treatment at the time of the birth, rather than from effects on prenatal care. 


\section{Methods}

\subsection{A Model of Medicaid Participation, Prenatal Care, and the Production of Infant Health}

Our objective is to measure the effects of changes to the Medicaid programis on the mother's participation in prenatal care, and ultimately on infant health. We begin the discussion with a simple economic model that relates participation in Medicaid to the production of infant health and serves to motivate our empirical analyses. The decision making agent is the expectant mother, who derives utility $U$ from both a numeraire consumption good denoted by $C$ and from infant health, or quality, denoted by $Q$. Infant health can be influenced by purchasing an investment good such as prenatal care, denoted by I. Public health insurance amounts to a subsidy of the investment good $I$; the price of the good, denoted by $\Pi$, is lower for consumers who participate in the program than for those who do not participate. At the same time, however, participating in Medicaid may cause the consumer to feel stigmatized. We assume that stigma associated with participating in the program reduces utility by an amount denoted by $\Theta .^{2}$

We assume that it is costly to participate in the program, since it may require effort to apply for the program and maintain eligibility for benefits. Application costs may involve both time costs and outof-pocket costs for travel; if the primary costs are time costs, then it may be reasonable to posit that the costs of participation are proportional to income $M$. We make this assumption for the sake of simplicity, although additive costs would not qualitatively affect the analysis.

Upon becoming eligible for benefits, the mother's problem is to decide whether to participate in the program and to choose optimal values of $C$ and $I$. The solution to this problem involves solving for optimal $C$ and $I$ conditional on participation and then choosing whether to participate so as to maximize utility. Conditional on not participating, the consumer solves the following problem:

2 Moffitt (1983) refers to this as "flat" stigma, since it arises from participating in the program at all, and is independent of the degree of participation. 
$\max$ $U(C, Q ; X, \Phi)$

$C, I$

subject to

$$
\begin{array}{ll}
Q=f(I) & f^{\prime}>0, f^{\prime \prime}<=0 \\
C+\Pi_{n p} I=M &
\end{array}
$$

where $\Pi_{n p}$ is the price of $I$ in the absence of the program subsidy. The vector $X$ denotes a set of observable exogenous attributes of the mother that affect her tastes, and $\Phi$ denotes a set of unobservable maternal attributes that also affect her preferences. The function $f()$ is referred to as the quality production function; it captures the technological and biological means by which investments in infant health, such as prenatal care, translate into better infant health. We assume that this relationship obeys diminishing marginal productivity. That is, greater investments in infant health lead to improvements in infant health, but in a manner that diminishes with the level of the investment. ${ }^{3}$

The optimal values of $C$ and $I$ are given by the demands $C_{n p}{ }^{*}=C^{*}\left(\Pi_{n p} M ; X, \Phi\right)$ and $I_{n p}{ }^{*}=I^{*}\left(\Pi_{n p} M ; X, \Phi\right)$. When the demands are inserted back into the utility function, one obtains the consumer's maximized (or indirect) utility conditional on non-participation as $V_{n p}{ }^{*}=V\left(\Pi_{n p} M ; X, \Phi\right)=U\left(C^{*}\left(\Pi_{n p}, M ; X, \Phi\right), I^{*}\left(\Pi_{n p}, M ; X, \Phi\right)\right)$.

Conditional on participating, the consumer solves the problem:

$\max \quad U(C, Q ; X, \Phi)-\Theta$

$C, I$

subject to $\quad Q=f(I) \quad f^{\prime}>0, f^{\prime \prime}<=0$

$$
C+\Pi_{p} I=M(1-k)
$$

where $\Pi_{p}<\Pi_{n p}$ is the price of $I$ in the presence of the program subsidy and $k M$ is the cost of participating in the program. The solution of this problem yields demands $C_{p}^{*}=C^{*}\left(\Pi_{p}, M(1-k) ; X, \Phi\right)$ and

\footnotetext{
${ }^{3}$ One could also allow the production function to vary with observable and unobservable characteristics of the mother. Doing so explicitly, however, would merely add notational clutter without substantially changing the implications for the empirical work that flow from the model.
} 
$I_{p}^{*}=I^{*}\left(\Pi_{p} M(1-k) ; X, \Phi\right)$ and indirect utility of: $V_{p}^{*}=V\left(\Pi_{p}, M(1-k) ; X, \Phi\right)-\Theta=U\left(C^{*}\left(\Pi_{p}, M(1-k) ; X, \Phi\right), I^{*}\left(\Pi_{p}, M(1-\right.\right.$ $k) ; X, \Phi))-\Theta$

The model implies that the consumer will participate in Medicaid if and only if:

$$
V\left(\Pi_{p} M(1-k) ; X, \Phi\right)-\Theta-V\left(\Pi_{n p^{p}} M ; X, \Phi\right)>0
$$

Equation (1) yields several implications that are useful for structuring our study of the effect of administrative reforms on the behavior and birth outcomes of pregnant women. First, anything that increases the value of the subsidy provided by the program will increase participation rates. Likewise, anything that decreases the cost of participation or the stigma associated with participating will also increase participation. Second, the same factors that influence prenatal participation in Medicaid will also influence infant health, if prenatal care is at all effective.

Many of the administrative reforms adopted in the 1990s were intended precisely to lower the costs and/or raise the benefits associated with participation in Medicaid by pregnant women. Specifically, presumptive eligibility and expedited application processing seem likely to raise the benefit provided by the program by giving health care providers an incentive to provide care even prior to a final determination of eligibility. Reforms such as shortening applications should reduce the cost of applying for Medicaid. Allowing mail-in applications (rather than face-to-face interviews) both reduces costs and may reduce stigma. On the other hand, cutting welfare roles can be expected to increase the costs of applying for Medicaid, other things being equal.

\subsection{The Effects of Administrative Procedures on Prenatal Care}

The model can be used to motivate an empirical model of the decision to obtain prenatal care of the form:

(2) $P_{s t i}{ }^{*}=a A D M I N_{s t}+b C U T O F F_{s t}+c W E L F A R E+d U N E M P+e X_{s i i}+u_{s}+v_{t}+\varepsilon_{s t i}$ for $s=1, \ldots, S, t=1, \ldots, T$; and $i=1, \ldots, N_{s l}$, where $P^{*}$ is participation in prenatal care by the $i^{\text {th }}$ expectant 
mother in the $s^{t h}$ state at time $t . A D M I N_{s t}$ is a vector of dummy variables indicating whether each of the administrative reforms was in effect in state $s$ at period $t ; C U T O F F_{s t}$ is a variable giving the income eligibility cutoff in effect in state $s$ during period $t$ as a percentage of the poverty level; WELFARE gives the rate of participation in welfare among women in the state; and UNEMP is included in order to control for business cycle conditions that are expected to influence WELFARE, as discussed above. The terms $a, b, c, d$ and $e$ are coefficients to be estimated from the data. The term $X_{s i t}$ is the vector of observable exogenous maternal characteristics that influence participation, such as maternal age and education.

The unobservable determinants of prenatal care utilization, denoted by $\Phi$ in the discussion above, are decomposed here into three mutually independent components for the purposes of the regression analysis. The first component, $u_{s}$, is a state effect, common to all pregnant women in state $s$. This term can be thought of as representing characteristics of a state which change only slowly over time such as the demographic composition of the state. The term $v_{t}$ denotes a period effect, common to pregnant women at period $t$. This term can be thought of as representing things like the technology available to women at date $t$. Finally, $\varepsilon_{\mathrm{sti}}$ is a person-specific error term, capturing all purely idiosyncratic factors that influence participation. Since our dependent variables are zero-one indicators, we present logit estimates below. ${ }^{4}$

The large size of the VSDN data set offers many advantages that are discussed further below. However, it also raises a specification issue, first analyzed by Moulton (1986). Since our dependent variables vary at the level of the individual, and the policy variables vary only between state-period cells, logit estimates will tend to overstate the precision with which the coefficients of the policy variables are estimated. To account for this problem, we adapt Moulton's approach to our setting by computing standard errors that allow for arbitrary dependence amoung the individual-level error terms within each state-year cell.

4 Probit estimates were impractical given the large size of our data set. 


\subsection{Estimating the Effects of Administrative Reforms on Birthweight}

If the policy variables increase the utilization of prenatal care, and if the marginal prenatal care obtained has an effect on infant health, then the policy variables should have an impact on infant health as measured by birthweight. We examine the effect on birthweight in two ways. First, we estimate reduced form models of the effects of the policy variables on low birthweight and very low birthweight. These logit models are of the same form as equation (2). A limitation of these models is that we cannot be certain that any measured effect of the policy is coming through the utilization of prenatal care, rather than through some other channel. In particular, welfare rates might be expected to affect infant health through an income effect, as well as by facilitating access to prenatal care under the Medicaid program.

Hence, we also estimate TSLS models of the effects of prenatal care on health outcomes using the policy variables as instruments. These models allow us to assess the extent to which the policy measures affect infant health through their effects on prenatal care, rather than through other channels.

\section{The Data}

The main source of data for this study is the Vital Statistics Detailed Natality Files for 1990 to 1996. The natality data is collected from birth certificates, and is a census of virtually all of the approximately 4 million births that occur in the United States each year. The U.S. Standard Birth Certificate is reproduced as Appendix Figure 1. The large sample size facilitates the analysis of relatively rare outcomes, such as very low birthweight, and enables us to conduct separate examinations by race and socioeconomic status. A limitation of the VSDN is that it does not have information about Medicaid coverage, nor does it have the income data necessary to reliably impute Medicaid eligibility or coverage. Thus, we will use this data to see whether prenatal care and birthweight are affected by the state-level differences in policy, rather than to examine Medicaid enrollments per se. Data about fetal deaths come from the Vital Statistics Fetal Deaths Detail Record, which follow much the same format as the birth records. 
Table 3 shows the utilization of prenatal care and birthweights, by race. In addition, in order to examine the effects of socioeconomic status without reference to race, figures for whites are broken out separately for teen mothers and highschool dropouts as well as for college graduates (those with 16 years of education or more). These figures are calculated using the pooled VSDN data for 1990 to 1996 . We focus only on singleton births, since multiple births are much more likely to be of low birthweight for reasons that are unlikely to be related to use of prenatal care. We divide the children using the race of the mother, in order to avoid issues regarding classification of children born to mothers and fathers of differing race (approximately 4\%), or classifying children whose father's race is not reported (approximately 16\%). In this we are following the National Center for Health Statistic's practice as of 1989. Hispanics, Asians and a small residual "other" category consisting largely of Native Americans, Pacific Islanders, and persons who did not report maternal race are not included in this analysis.

For "all whites", we use a $25 \%$ random sample, while for blacks, we use all of the available observations. This algorithm yields sample sizes for blacks of approximately the same size as those available for whites. Thus, if we find effects for whites but not for the other two groups, then this pattern of results cannot be attributed solely to differences in sample size. However, the sample of white teen mothers and dropouts includes all of the teen mothers and dropouts in the data, that is, it is not a subset of the "all whites" data set. In practice, $14 \%$ of white mothers had less than a highschool education, $6 \%$ were teen mothers. For blacks, the comparable figures were $29 \%$ and $16 \%$.

Table 3 shows striking racial differences, some of which have been documented in previous studies. Blacks are three times more likely than whites to have children of very low birthweight. Whites are more likely than blacks to be reported to have received "adequate" prenatal care, judged in terms of both the timing of the initiation of prenatal care and the number of visits; they are also much more likely to have begun care in the first trimester, and much less likely to have gone without any prenatal care. 


\section{Results}

\subsection{Effects of Policy on Prenatal Care}

Estimates of the effects of the Medicaid policy variables on our measures of utilization of prenatal care are shown in Table 4. In addition to the control variables shown in the table, these models also included the year and state variables discussed in section 3 above. We did not include information about the father's age and education in these regressions because it is often missing, and because when it is present it is highly correlated with the mother's information. The control variables generally have the effects one would anticipate on the basis of the previous literature. For example, older mothers, more educated mothers, and married mothers are more likely to get prenatal care than teens, less educated women, or unmarried women. Utilization of prenatal care also decreases with parity.

Table 4 suggests that increases in the income cutoff have statistically significant effects on all three measures of prenatal care utilization. Income cutoffs have been normalized so that a cutoff of $100 \%$ of poverty is equal to $1,200 \%$ of poverty is equal to 2 and so on. Since logit coefficients are difficult to interpret, Table 4 also gives the derivatives implied by the coefficient estimates. These figures imply that a change in the income cutoff from 100 to $200 \%$ of poverty would have reduced the probability of inadequate prenatal care by 1 percentage point among whites and by 2 percentage points among blacks. Relative to the means shown in Table 3, these numbers represent reductions in the probability that care was inadequate of $25 \%$ among whites and $16 \%$ among blacks. Similarly, the estimates imply that this change in the income cutoff would have reduced the fraction of women going without prenatal care by about a third of a percentage point among whites, and by a half percentage point among blacks. Finally, this change in the income cutoff is estimated to have reduced the probability that prenatal care was delayed beyond the first trimester by 2 percentage points for whites and 5 percentage points for blacks, a reduction of $13 \%$ and $15 \%$, respectively.

Increases in the welfare rate also had significant effects on the utilization of prenatal care. A 2 
percentage point change in the welfare rate (such as occurred in California between 1990 and 1996) was associated with an approximately half a percentage point reduction in the probability of inadequate prenatal care among whites. But the same change was associated with an almost 2 percentage point reduction among blacks. A two percentage point change would also have reduced the probability of no prenatal care by approximately 1 percentage point among blacks, as well as reducing the probability of late prenatal care by 2 percentage points. Reductions in these measures among whites were smaller.

The significant effects of increases in the welfare rate can be compared to the generally small and insignificant effects of the unemployment rate. The fact that welfare rates are significant determinants of prenatal care utilization, while a more general indicator of economic conditions is not, suggests that welfare rates may in fact impact prenatal care through the administrative link to the Medicaid program rather than strictly through an income effect, a hypothesis that will be tested further below. That is, women who lose access to welfare also appear to reduce utilization of prenatal care, presumably because it is more difficult for them to access the Medicaid program.

In contrast to the income cutoffs and welfare rates, the administrative reforms we consider have generally insignificant effects on the utilization of prenatal care. Only mailin applications are estimated to have a positive effect on prenatal care, and then only in the model of late prenatal care among whites. Shortened forms and expedited or presumptive eligibility have wrong-signed effects in the 4 instances in which coefficients are statistically significant.

We have considered three possible explanations for this perverse pattern of estimated effects on the administrative reform variables. First, our estimates could be biased by fetal selection. If the administrative reforms caused some babies who received inadequate prenatal care to survive when they would otherwise have died (suppose they got some crucial prenatal care but not the desired amount), then we might find that the administrative reforms were associated with reduced utilization of prenatal care among surviving infants. However, we found using models similar to equation (2), that the administrative 
reforms had little effect on the probability that a fetus that had been carried at least 20 weeks ultimately survived. Moreover, re-estimating our models using the sample of pregnancies that lasted at least 20 weeks produced very similar results.

A second possibility is that the administrative reforms affected the way that birth certificates were completed. Birth certificates are usually filled out by the attending physician using information collected from the mother. Birth certificates that are filled out by a physician who has attended a woman throughout her pregnancy may have fewer missing values than those that are filled out by a doctor who has never seen the mother before. Suppose that administrative reforms lead to greater continuity of care, and hence to fewer missing values. If the data that would have been missing comes from women who nevertheless received inadequate prenatal care, then we might spuriously conclude that administrative reforms reduced the utilization of prenatal care. One difficulty with this potential explanation is that changes in the income eligibility cutoffs and in welfare caseloads, which might also be expected to lead to greater continuity of care, are estimated to have right-signed effects in contrast to the administrative reforms. In order to pursue this "missing data" hypothesis further, we estimated models similar to equation (2) in which the dependent variable was the probability that prenatal care information was missing from the birth certificate. However, we found that the administrative reforms had generally insignificant effects on the probability that data was missing.

A third possibility is that the administrative reforms really did have perverse effects. Suppose that there are some women who do not particularly value prenatal care, but who do want to make sure that they gain Medicaid coverage of their deliveries. Then making it faster and easier to enroll by shortening applications and processing them faster might simply encourage these women to delay enrollment until just prior to delivery. If we assume that more educated women are more likely to value prenatal care, then one might expect the wrong-signed effects to be larger for more disadvantaged women than for all women (or college graduates). This hypothesis is investigated below, when we present estimates for disadvantaged 
and college-educated whites.

\subsection{Reduced Form Estimates of Effects of Policy Variables on Birthweight}

Table 5 shows estimates of the effects of the policy variables on the probabilities of low birthweight and very low birthweight. These models are of the same form as those in Table 4, but for the sake of brevity, the coefficients on the control variables are not shown. These coefficients follow the patterns one would expect given the existing literature. For example, married mothers, and mothers who are more educated have healthier babies, while older mothers are more likely to have unhealthy babies. Also, males are more likely to suffer low or very low birthweight than females. The probability of low or very low birthweight is also highest for first born children but does not change appreciably with increasing parity.

Table 5 suggests that increases in the income eligibility cutoffs for Medicaid had a significant negative effect on the probability of very low birthweight among whites (although the coefficient is significant only at the $90 \%$ level rather than at the $95 \%$ level of confidence). However, the effect is small-the incidence of very low birthweight is reduced by only one tenth of a percentage point and there is no statistically significant effect on the incidence of low birthweight. Together, the estimates for very low birthweight and low birthweight suggest that the income cutoffs are causing some infants who would otherwise be of very low birthweight, to be born with somewhat higher, but still low, birthweights.

Among blacks, increases in the income cutoff have no significant effects on birthweight, but increases in the welfare rate are estimated to reduce both the incidence of very low birthweight and of low birthweight. The incidence of very low birthweight among blacks is reduced by 2 percentage points for every 1 point increase in the welfare rate. Once again, the effects of the welfare rate can be compared to those of the unemployment rate. Table 5 indicates although the unemployment rate had little consistent effect on the utilization of prenatal care, it has a consistently negative effect on birthweights. This result 
suggests that birthweights are affected both by the economic circumstances of households as well as by prenatal care.

The administrative reforms we consider have no statistically significant effects on birthweights. This result suggests that if reforms such as shortening forms and expediting eligibility determination do encourage women to delay obtaining prenatal care, then these delays have no effect on health. A possible reason is that only women who anticipate a healthy birth are encouraged to delay by these administrative measures.

Our analysis of fetal selection suggested that the true impact of increases in the income cutoffs and in welfare rates may be under-estimated by the models shown in Table 5. Higher income cutoffs reduced the probability of fetal death (after 20 weeks gestation) among both whites and blacks, while higher welfare rates reduced it among blacks. If fetuses who are "saved" by these policy measures are of lower birthweight than other fetuses, then fetal selection will cause improvements in birthweight induced by the policy variables to be understated by our estimates.

Such fetal selection may operate either through improved prenatal care, or through more intensive interventions at the time of the birth. Additional information given on the death certificates suggests that a significant fraction of the fetal deaths that occur after 20 weeks, occur during attempted deliveries. Hence, the outcome may have been affected by improvements in the technology available to the mother, which in turn is affected by the mother's insurance status. ${ }^{5}$ Since the policy variables may affect outcomes either through effects on prenatal care or through other pathways (such as more intensive treatment at the time of the birth), it is of interest to examine the direct effect of the changes in prenatal care that were induced by the policy changes on infant outcomes.

5 See Currie and Gruber (1999) who show that women who move from being uninsured to having Medicaid coverage are likely to get more intensive treatments at the time of delivery. 


\subsection{TSLS Estimates of the Effects of Prenatal Care on Birthweight}

Table 6 explores the relationship between the changes in prenatal care induced by policy changes and birthweight by comparing estimates obtained using linear probability models to those obtained using TSLS. We have adopted linear models in this section for ease of implementation of our instrumental variables procedure. We found that linear probability models similar to those shown in Tables 4 and 5 produced very similar results to those shown in those Tables. The linear probability models suggest that inadequate prenatal care, and failure to obtain prenatal care are both strongly associated with lower birthweights. As one might expect, the estimated effects suggest that failure to obtain any prenatal care is much worse than obtaining care that is merely inadequate. Failure to obtain care in the first trimester has very small effects, and is "wrong-signed" in the models of very low birthweight. These estimates suggest that mothers who anticipate healthy births are more likely to delay obtaining prenatal care, and that this delay may not have any adverse health consequences in most cases.

These estimates also highlight the need for controlling for selection when attempting to measure the effects of prenatal care. Women who obtain no prenatal care, or inadequate care, could be similarly positively selected, which would mean that the OLS estimates of the effects of these measures were biased downwards. On the other hand, women who obtain no prenatal care, or inadequate care, might be negatively selected in that they have other unobserved characteristics that one would expect to be associated with lower birthweights. In this case, OLS estimates would overstate the effectiveness of prenatal care.

Table 6 shows TSLS estimates calculated using all of our policy measures (income cutoffs, welfare rates, and the three administrative measures), as instruments. The maintained hypothesis here is that these variables affect birthweight only through their effects on prenatal care.

The results suggest that among whites, our three indices of prenatal care have little effect on birthweights. The sole exception is that inadequate prenatal care has a marginally significant $(t=1.81)$ positive effect on 
the probability of very low birthweight. Among blacks, however, the estimates suggest that both lack of prenatal care, and inadequate prenatal care reduce birthweights. Moreover, the estimates are of similar magnitudes to those of the linear probability models.

Under the null hypothesis that income cutoffs are a valid instrument, we can use overidentification tests to test the assumption that welfare rates affect birthweight only through effects on prenatal care. This assumption cannot be rejected for whites. However, for blacks, the overidentification test is rejected in 5 out of 6 models (the exception being the model of the effect of delayed prenatal care on very low birthweight). Hence, for blacks we also estimated TSLS models that excluded welfare rates from the instrument list. In these models, the estimated effects of prenatal care were not statistically significant.

Recall that the reduced form estimates shown in Table 5 suggested that increasing the income cutoff for Medicaid eligibility reduced very low birthweight (but not low birthweight) among whites, but had no effect among blacks. The TSLS results confirm these findings. The coefficient of .038 in the TSLS model of very low birthweight for whites suggests that increases in the adequacy of prenatal care that were induced by the increases in income eligibility reduced the incidence of very low birthweight by 4 percentage points among those who were moved from inadequate to adequate care. The fact that changes in income eligibility had no effect on low birthweight suggests that the main impact on health was to move babies from the very low birthweight to the low birthweight category.

Among blacks, we saw in Table 4 that both higher income cutoffs and higher welfare rates were associated with improvements in the utilization of receipt of prenatal care. The reduced form estimates in Table 5 suggested however, that only changes in welfare rates affect birthweight. The TSLS evidence discussed above suggests first that changes in the welfare rate affect black birthweights through some mechanism other than their effects on prenatal care. Second, they suggest that the improvements in the use of prenatal care that were induced by changes in income cutoffs and the welfare rate had little impact 
on black birthweights.

\subsection{Estimates by Socioeconomic Status}

We have estimated all of our models on two subsamples, whites with 16 or more years of education, and whites who are teen mothers or highschool dropouts. If the effects we estimate are really due to changes in access to Medicaid rather than to some concurrent change in the policy environment, then we expect them to be larger for teens and dropouts as this group is more likely to have been affected by the policy changes. Note that there is scope for these measures to have some affect on collegeeducated women--using the 1996 Current Population Survey, we found that $8 \%$ of 15 to 44 year old college educated women with infants in the household reported receiving Medicaid in the past year. Estimates of the probability of obtaining inadequate or late prenatal care are shown in Table 7. Since very few college-educated women received no prenatal care, we do not show this outcome.

Table 7 suggests that as anticipated, the income cutoffs and welfare rates have larger effects on prenatal care utilization in the disadvantaged group than for the college educated. Similarly, shortening the application form has significant (wrong-signed) effects only on the teens and dropouts. Thus, if shortening the form is encouraging some women to delay obtaining prenatal care, it appears to have this effect only among the disadvantaged. The one anamolous result is that expedited or presumptive eligibility increases delay in obtaining prenatal care only among the college educated.

We also estimated models similar to those in Table 5 for these two groups. Although the effect of income cutoffs on the probability of low birthweight was much larger for disadvantaged whites than for the college educated (the logit coefficients were -.068 vs. .001 ), it was not statistically significant in either group. We were also unable to obtain precise estimates of the effects of prenatal care on the disadvantaged in our TSLS models. 


\section{$\underline{5.5 \text { Extensions and Caveats }}$}

While our measures of prenatal care capture important aspects of prenatal care and are frequently used in the literature, it should be kept in mind that they are primarily quantitative measures which say little about the quality of care received. There is evidence that quality matters. One recent study of a national sample of mothers found that those who had received all of the types of advice recommended by the Expert Panel on the Content of Prenatal Care were more likely to have babies of healthy birthweight than those who had not (Kogan et al; 1994). The recommended advice covers: reducing or eliminating alcohol, smoking, and illegal drugs; eating the proper foods; taking vitamin supplements; and gaining an appropriate amount of weight during the pregnancy. It is possible that our policy measures affect the quality as well as the quantity of care, but that it is the quality of care that matters most for improving outcomes such as birthweight.

It is also possible that our policy measures are correlated with some ommitted variable that also affects birthweights. In this case, the reduced form estimates shown in Table 5 will be biased, and the policy measures will not be valid instruments. Suppose for example, that higher Medicaid income cutoffs induced some women who would have aborted to carry their infants to term, and that these infants are both less likely than others to receive adequate prenatal care and more likely than others to be of low birthweight (c.f. Grossman and Jacobowitz, 1981, Grossman and Joyce, 1990 and Currie, Nixon and Cole, 1996). Then omitting abortion rates from our models will cause us to under-estimate the positive effects of the higher income cutoffs. Unfortunately, it is difficult to test this hypothesis since abortion rates are available for only two years of our sample period.

Anti-smoking policies could also affect birthweight since smoking is the single most important preventable cause of low birthweight. And it is possible that anti-smoking policies such as cigarette tax increases coincided with changes in Medicaid policy. For example, legislators seeking to pay for the higher income cutoffs for Medicaid might raise cigarette taxes. In this case, reductions in the incidence 
of low birthweight which were really due to reductions in smoking would be falsely attributed to increases in the generosity of the Medicaid program. Reductions in smoking could conceivably also affect the utilization of prenatal care through fetal selection. Suppose, for example, that female smokers were less likely than other women to get adequate prenatal care, and that some fraction of smokers who would have miscarried go on to carry a child to term because of increases in cigarette taxes. Then once again, the effects of the Medicaid policy variables on utilization of prenatal care would tend to be understated.

In order to test these hypotheses, we re-estimated all of our models including the cigarette tax for each state and year. William Evans was kind enough to provide us with time-series data on state cigarette taxes (in cents per pack). However, while cigarette taxes did have significant effects on birthweight, their inclusion in our models did not change any of the findings reported above.

\section{Conclusions}

Our results show that changes in welfare rates and increases in the income eligibility cutoffs for the Medicaid program above $133 \%$ of the poverty line both had significant effects on the utilization of prenatal care. The findings concerning income cutoffs can be compared to those of Currie and Gruber (1996) who found that increases in income cutoffs in an earlier period (1987 to 1992) were largely ineffective in drawing women into prenatal care and improving infant health outcomes. They speculated that the women who became eligible were unaware of their new entitlement. Our estimates are for a later period and suggest that awareness of the program has risen over time:

The fact that welfare rates have an impact on the utilization of prenatal care shows that the administrative link between welfare and Medicaid remains important, even in the face of dramatic expansions in income eligibility for the program, and the adoption of many administrative reforms intended to simplify enrollment. Although our sample period predates the most recent round of welfare reform, our results indicate that among pregnant women, cuts in the welfare rolls are likely to be 
accompanied by reduced use of prenatal care by both whites and blacks.

It is more difficult to say what the effects will be on infant health. Our estimates suggest that among whites, increases in the use of prenatal care related associated with higher income cutoffs reduced the incidence of very low birthweight. This effect is riather small--the incidence of very low birthweight is reduced by only one tenth of a percentage point--and there is no statistically significant effect on the incidence of low birthweight. Among blacks, we find little evidence that changes in prenatal care utilization associated with higher income cutoffs or lower welfare rates had any impact on birthweights. However, welfare rates did appear to have significant effects on black birthweights, presumably through a mechanism other than links between welfare and use of prenatal care.

We find little evidence that administrative reforms intended to increase the utilization of prenatal care have been effective. Administrative barriers to care have been extensively criticized in the public health literature (c.f. Brown, 1989; Kalmuss and Fennelly, 1990, and Aved et al., 1993). The administrative reforms we examine can be regarded as direct responses to these criticisms on the part of state government. An important caveat to our results, is that due to the limitations of our sample, we have been unable to conduct a direct assessment of the impact of two potentially important administrative changes, the elimination of asset tests, and the effects of outstationing eligibility workers. However, we can infer from our results regarding the relationship between welfare rates and use of prenatal care that the administrative reforms were not enough to break the link between welfare and access to prenatal care under the Medicaid program. 
Table 1: Number of States Adopting Various Strategies to Encourage the Medicaid Enrollment of Pregnant Women

\section{Income Cutoff ShorteneBresumptive/ExpeditedMail-in} $>133 \%$ Poverty Application Eligibility Application

$\begin{array}{lllll}\text { Jan. } 1990 & 20 & 19 & 31 & 1^{*} \\ \text { July 1990 } & 23 & 25 & 35 & 2^{*} \\ \text { Jan. 1991 } & 23 & 27 & 38 & 5^{*} \\ \text { July 1991 } & 29 & 31 & 39 & 14 \\ \text { Jan. 1992 } & 29 & 33 & 38 & 23 \\ \text { July 1992 } & 31 & 28 & 40 & 17 \\ \text { Jan. 1993 } & 32 & 26 & 39 & 16 \\ \text { July 1993 } & 33 & 41 & 43 & 18 \\ \text { Jan. 1994 } & 33 & 42 & 44 & 20 \\ \text { July } 1994 & 33 & 42 & 44 & 20 \\ \text { Feb. 1995 } & 33 & 43 & 44 & 19 \\ \text { Aug. 1995 } & 34 & 43 & 44 & 26 \\ \text { Feb. 1996 } & 35 & 41 & 44 & 31\end{array}$

Notes: Source is National Governors' Association, Matemal and Child Health Update, various issues. The dates in the table correspond to the dates of the issues. An asterisk indicates that the data comes from discussion in the text of the sources rather than being drawn from the tables in those sources. 
Table 2: Welfare Rates and Unemployment Rates in 10 Large States

California

Florida

Illinois

Massachusetts

Michigan

New Jersey

New York

Ohio

Pennsylvania

Texas
1993

1996

Welfardnemp.WelfardUnemp. WelfardUnemp.

Rate Rate Rate Rate Rate Rate

$\begin{array}{llllll}7.3 & 5.8 & 9.0 & 9.4 & 9.2 & 7.2\end{array}$

$\begin{array}{llllll}3.6 & 6.0 & 6.2 & 7.0 & 4.6 & 5.1\end{array}$

$\begin{array}{llllll}6.4 & 6.2 & 6.8 & 7.5 & 6.2 & 5.3\end{array}$

$\begin{array}{llllll}5.2 & 6.0 & 6.2 & 6.9 & 4.4 & 4.3\end{array}$

$\begin{array}{llllll}8.1 & 7.6 & 8.3 & 7.1 & 6.0 & 4.9\end{array}$

$\begin{array}{llllll}4.7 & 5.1 & 5.1 & 7.5 & 4.1 & 6.2\end{array}$

$\begin{array}{llllll}6.4 & 5.3 & 7.7 & 7.8 & 7.4 & 6.2\end{array}$

$\begin{array}{llllll}6.8 & 5.7 & 7.4 & 6.5 & 5.6 & 4.9\end{array}$

$\begin{array}{llllll}5.3 & 5.4 & 6.0 & 7.1 & 5.2 & 5.3\end{array}$

$\begin{array}{llllll}4.1 & 6.3 & 4.9 & 7.2 & 3.9 & 5.6\end{array}$ 
Table 3: Incidence of Selected Outcomes by Race and Socioeconomic Status 1990-1996

\begin{tabular}{|c|c|c|c|c|}
\hline & Whites & Blacks & $\begin{array}{l}\text { White Teens } \\
\text { \& Dropouts }\end{array}$ & $\begin{array}{l}\text { White } \\
\text { College }\end{array}$ \\
\hline Very Low Birthweight & .008 & .026 & .012 & .005 \\
\hline Low Birthweight & .047 & .119 & .075 & .032 \\
\hline Inadequate Prenatal Care & .038 & .135 & .102 & .011 \\
\hline Late Prenatal Care & .142 & .316 & .314 & .052 \\
\hline No Prenatal Care & .007 & .038 & .020 & .000 \\
\hline $\begin{array}{l}\text { Very Low Birthweight } \\
\text { if Inadequate Care }\end{array}$ & .016 & .037 & .017 & .009 \\
\hline $\begin{array}{l}\text { Low Birthweight if } \\
\text { Inadequate Care }\end{array}$ & .094 & .184 & .108 & .053 \\
\hline $\begin{array}{l}\text { \% Missing Prenatal Care } \\
\text { Adequacy }\end{array}$ & .032 & .065 & .039 & .024 \\
\hline \# Observations & 4309664 & 2670038 & 4323776 & 4261148 \\
\hline
\end{tabular}

Notes: Number of observations is not the same for all outcomes. The number shown here refers to the number of non-missing observations for birthweight. Note that the "all white" column is a $25 \%$ sample of the available observations for whites while the numbers in the other three columns are based on all of the available observations. 


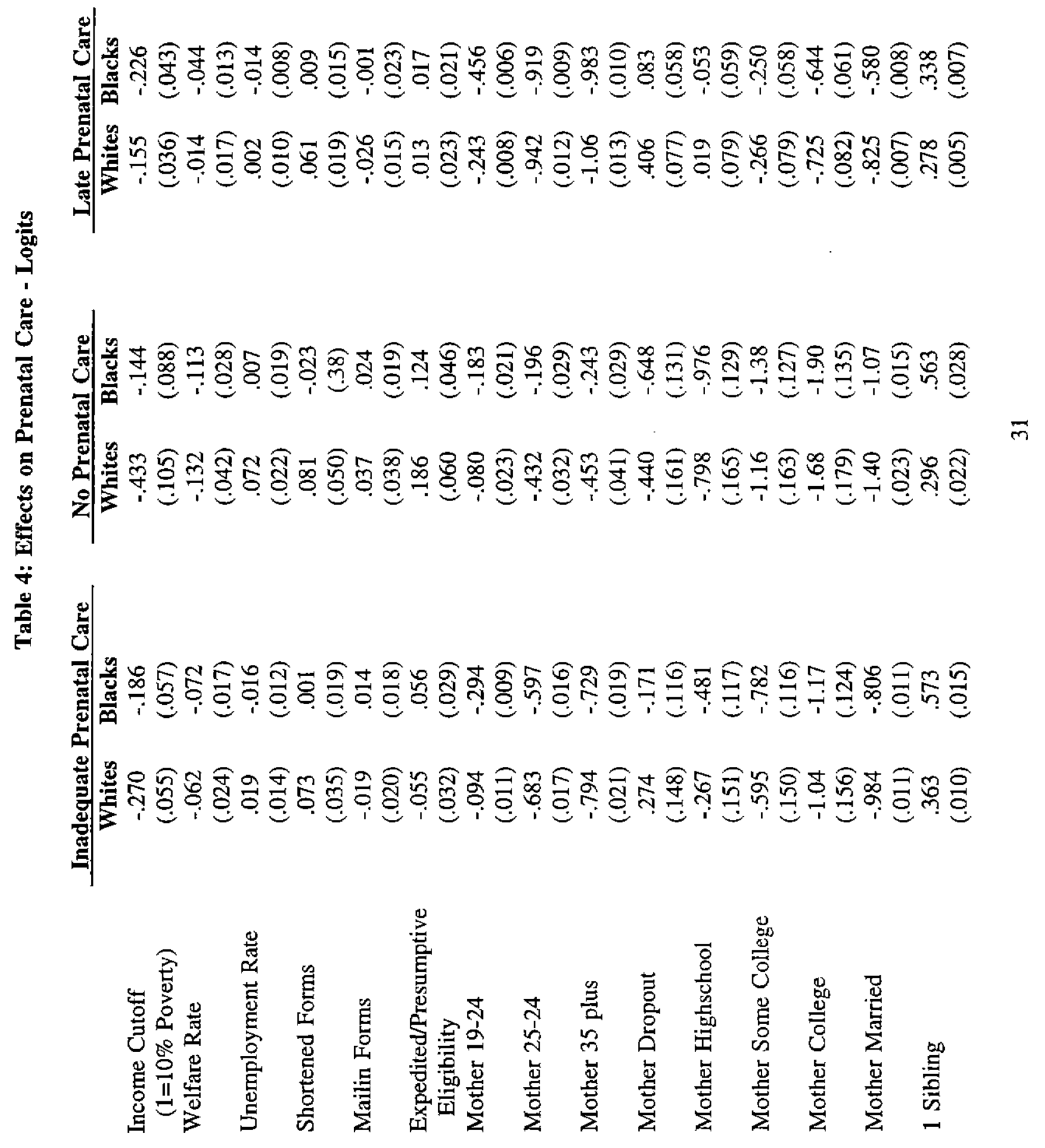




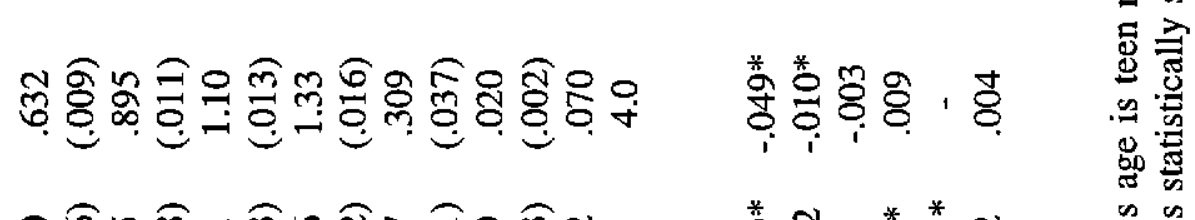

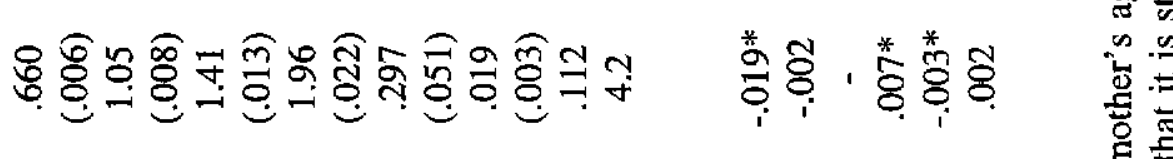

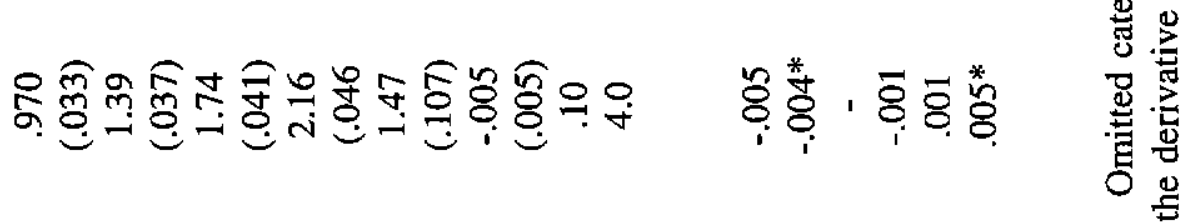

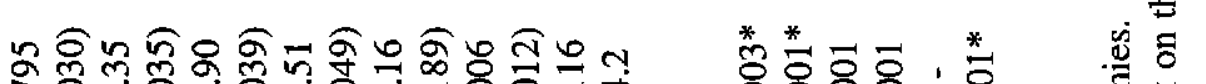
ल

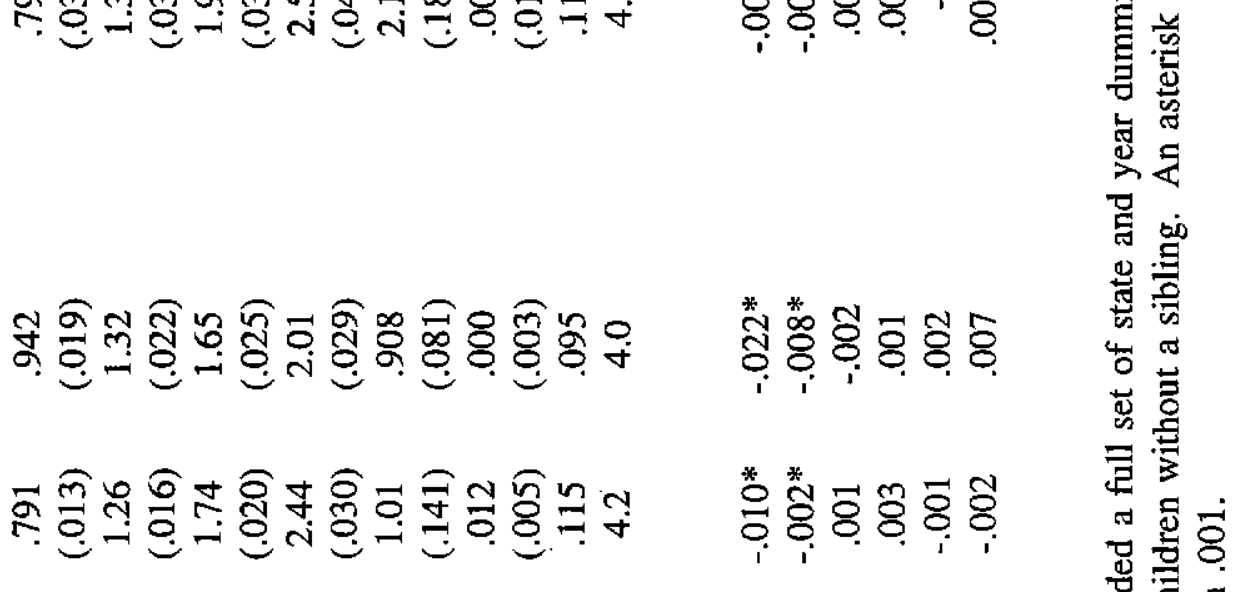

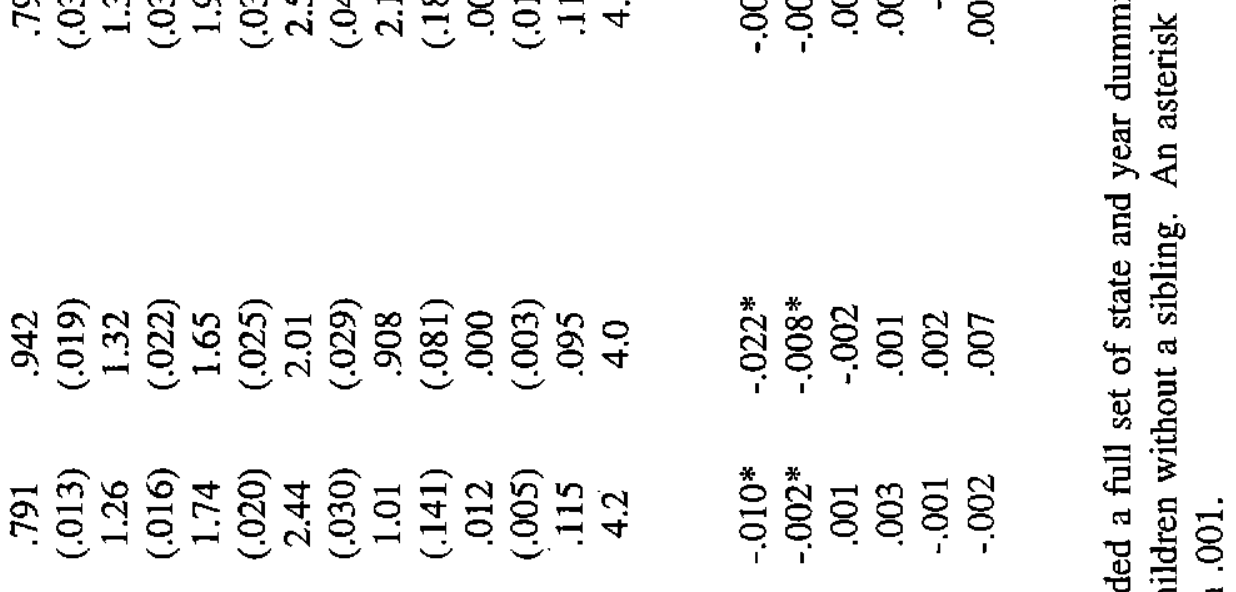

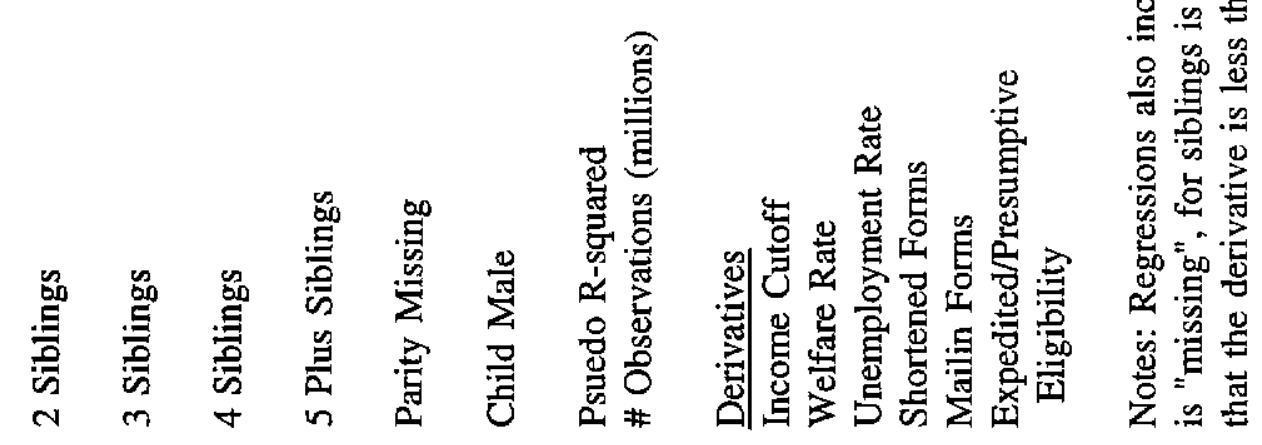


Table 5: Effects on Birthweight - Logits

Income Cutoff

Very Low Birthweight

White Black

( $1=100 \%$ Poverty)

$-.095$

$-.030$

$(.047)$

$(.030)$

Welfare Rate

$-.015$

$-.020$

(.019)

$(.009)$

Unemployment Rate

.030

(.011)

.024

$(.007)$

Shortened Forms

.019

$-.006$

$(.021)$

$(.013)$

$-.001$

$-.003$

(.019)

(.011)

Expedited/Presumptive

$-.021$

$-.022$

Eligibility

(.035)

(.021)

Low Birthweight

White

Black

$-.005$

.025

(.018)

(.016)

$-.009$

$-.022$

$(.007)$

(.005)

.009

.010

(.004)

(.004)

.000

.007

$(.009)$

$(.008)$

$-.002$

.009

(.008)

(.007)

$-.008$

$-.002$

(.014)

(.010)

Psuedo R-squared

.019

.010

.023

.013

\# Observations (millions)

4.3

4.3

4.3

4.3

Derivatives

Income Cutoff

Welfare Rate

Unemployment Rate

Shortened Forms

Mailin Forms

Expedited/Presumptive

$\begin{array}{cc}-.001^{*} & -.001 \\ - & -.001^{*} \\ - & .001 \\ - & - \\ - & - \\ - & .001\end{array}$

Eligibility

Notes: See Table 4. 
Table 6: OLS and TSLS Estimates of Effects of Prenatal Care on Birthweight

\section{OLS Tlack}

Dependent Variable: Very Low Birthweight

Measure of Prenatal Care:

Inadequate Prenatal Care

No Prenatal Care

.016

.071

$(.001)$

Late Prenatal Care
.045

$(.017)$

.075

$(.035)$

.019

$(.011)$

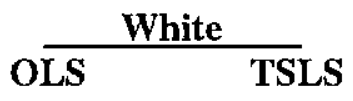

TSLS

$\begin{array}{cc}.008 & .038 \\ (.0004) & (.021) \\ .042 & .087 \\ (.001) & (.057) \\ -.001 & .010 \\ (.0001) & (.011)\end{array}$

$\begin{array}{lcccc}\text { Dependent Variable: Low Birthweight } & & & \\ \text { Measure of Prenatal Care: } & & & & \\ \text { Inadequate Prenatal Care } & .072 & .090 & .040 & .017 \\ & (.001) & (.043) & (.001) & (.051) \\ \text { No Prenatal Care } & .175 & .214 & .115 & .061 \\ & (.002) & (.089) & (.003) & (.152) \\ \text { Late Prenatal Care } & .0004 & -.08 & .005 & -.021 \\ & (.0005) & (.028) & (.0004) & (.029)\end{array}$

Notes: Each estimate in the table is from a separate regressions. The instruments include all of the policy variables (income cutoffs, welfare rates, and 3 indicators for administrative reforms). All regressions also included the other independent variables listed in Table 4. 
Table 7: Effects on Prenatal Care by Socio-Economic Status - Logits, Whites Only

\begin{tabular}{lcccc} 
& \multicolumn{2}{c}{ Inadequate Prenatal Care } & \multicolumn{2}{c}{ Late Prenatal Care } \\
\cline { 2 - 3 } & Disadvantaged & College & Disadvantaged & College \\
Income Cutoff & -.228 & .078 & -.191 & -.088 \\
$(1=100 \%$ Poverty) & $(.055)$ & $(.078)$ & $(.037)$ & $(.046)$ \\
Welfare Rate & -.092 & -.038 & -.034 & -.026 \\
& $(.021)$ & $(.033)$ & $(.015)$ & $(.018)$ \\
Unemployment Rate & -.006 & -.014 & .001 & -.030 \\
& $(.012)$ & $.021)$ & $(.008)$ & $(.015)$ \\
Shortened Forms & .083 & .049 & .053 & .030 \\
& $(.023)$ & $(.040)$ & $(.018)$ & $(.021)$ \\
Mailin Forms & -.003 & .043 & -.015 & -.021 \\
& $(.020)$ & $(.037)$ & $(.015)$ & $(.018)$ \\
Expedited/Presumptive & .078 & .079 & .031 & .053 \\
Eligibility & $(.032)$ & $(.064)$ & $(.028)$ & $(.023)$ \\
& & & & \\
Psuedo R-squared & .047 & .044 & .28 & .044 \\
\# Observations (millions) & 2.6 & 4.2 & 2.6 & 4.2 \\
& & & & \\
Derivatives & & .001 & $-.041^{*}$ & $-.004^{*}$ \\
Income Cutoff & $-.021^{*}$ & - & $-.007^{*}$ & -.001 \\
Welfare Rate & $-.008^{*}$ & $-.001^{*}$ \\
Unemployment Rate & -.001 & .001 &. & .001 \\
Shortened Forms & $.008^{*}$ & - & $.011^{*}$ & -.001 \\
Mailin Forms & - & .001 & .007 & $.003 *$ \\
Expedited/Presumptive & $.007^{*}$ & & & \\
Eligibility & & & &
\end{tabular}

Notes: See Table 4. 


\section{References}

Aved, Barbara M. et al., "Barriers to Prenatal Care for Low-Income Women," The Westem Journal of Medicine, 158 \#5 (May 1993) 493-498.

Bane, Mary Jo and Ellwood, David. Welfare Realities: From Rhetoric to Reform, (Cambridge: Harvard University Press) 1994.

Blank, Rebecca. It Takes A Nation (New York: Russell Sage) 1997.

Blank, Rebecca and David Card. "Recent Trends in Insured and Uninsured Unemployment: Is There an Explanation?," Quarterly Journal of Economics 106, November 1991, 1157-1190.

Blank, Rebecca and Patricia Ruggles. "When Do Women Use AFDC \& Food Stamps? The Dynamics of Eligibility vs. Participation," Joumal of Human Resources, 31 \#1, Winter, 1996, 57-89.

Bloom, Barbara. "Health Insurance and Medical Care", Advance Data from Vital and Health Statistics of the National Center for Health Statistics, \#188, (Washington D.C.: Public Health Service) Oct. 1, 1990.

Brown, Sarah C. "Drawing Women Into Prenatal Care", Family Planning Perspectives, 21 \#2, March/April, $1989,73-80$.

Chaikind, Stephen and Hope Corman. "The Special Education Costs of Low Birthweight," NBER Working Paper \#3461, October 1990.

Corman, Hope, Theodore Joyce, and Michael Grossman. "Birth Outcome Production functions in the United States", Journal of Human Resources, 22, Summer 1987, 339-360.

Creasy, R.K., B.A. Gummer, and G.C. Liggins, "System in Predicting Spontaneous Preterm Birth," Obstetrics and Gynecology, 6, 1980, 692ff.

Currie, Janet. "Do Immigrants Make Differential Use of Public Health Insurance?", in George Borjas (Ed.) Issues in the Economics of Immigration, (Chicago: University of Chicago Press) forthcoming.

Currie, Janet, and Jonathan Gruber. "Saving Babies: The Efficacy and Cost of Recent Changes in the Medicaid Eligibility of Pregnant Women," Journal of Political Economy, December 1996.

Currie, Janet and Jonathan Gruber. "The Technology of Birth: Health Insurance, Medical Interventions, and Infant Health," National Bureau of Economic Research Working Paper \#5985, Cambridge MA, 1997, revised spring 1999.

Currie, Janet and Duncan Thomas. "Medical Care for Children: Public Insurance, Private Insurance, and Racial Differences in Utilization," The Joumal of Human Resources, 30 \#1 (Winter, 1995) 135-162.

Currie, Janet, Lucia Nixon, and Nancy Cole. "Restrictions on Medicaid Funding of Abortion: Effects on Pregnancy Resolutions and Birth Weight", Journal of Human Resources, XXXI, 1996, 159-188. 
Cutler, David ad Jonathan Gruber. "Does Public Insurance Crowd Out Public Insurance?" The Quarterly Journal of Economics, 111 \#2 (May 1996) 391-340.

Ellwood, Marilyn and Genevieve Kenney. "Medicaid and Pregnant Women: Who is Being Enrolled and When?", Health Care Financing Review, 17 \#2, 7-28.

Fiscella, Kevin. "Racial Disparities in Preterm Births: The role of Urogenital Infections," Public Health Reports, v11, March/April 1996, 104-112.

Fossett, James W., et al. "Medicaid and Access to Child Health Care in Chicago", Journal of Health Politics, Policy, and Law, XVII, 1992, 273-298.

Frank, Richard, Donna Storbino, David Salkever, Catherine Jackson. "Updated Estimates of the Impact of Prenatal Care on Birthweight Outcomes by Race," NBER Working Paper \#3624, Cambridge, February 1991.

Grossman, Michael and Steven Jacobowitz. "Variations in Infant Mortality Rates among counties of the United States: The Roles of Public Policies and Programs", Demography, SVIII, 1981, 695-713.

Grossman, Michael and Theodore Joyce. "Unobservables, Pregnancy Resolutions, and Birth Weight Production Functions in New York City", Joumal of Political Economy, SCVIII, 1990, 983-1007.

Harris, Jeffrey. "Prenatal Medical Care and Infant Mortality," in Victor Fuchs, ed., Economic Aspects of Health, Chicago: University of Chicago Press, 1982.

Horbar, Jeffrey, Elizabeth Wright, Lynn Onstad et al., "Decreasing Mortality Associated with the Introduction of Surfactant Therapy: An Observational Study of Neonates Weighing 601 to 1300 Grams at Birth," Pediatrics, 92 \#2, August 1993, 191-196.

Institute of Medicine, Preventing Low Birthweight, Washington D.C.: National Academy Press, 1985.

Kalmuss, Debra and Katherine Fennelly, "Barriers to Prenatal Care Among Low-Income Women in New York City" Family Planning Perspectives, 22 \#5, Sept./Oct., 1990, 215-231.

Kogan, Michael D. et al. "Relation of the Content of Prenatal Care to the Risk of Low Birthweight", Journal of the American Medical Association, 221 \#17, May 4, 1994, 1340-1345.

Massey, Douglas S. and Nancy Denton, American Apartheid, (Cambridge MA: Harvard University Press, 1993).

McCormick, Barbara, et al., "The Health and Developmental Status of Very-Low-Birthweight Children at School Age," Journal of the American Medical Association, 267, 1992.

Moffitt, Robert A. "An Economic Model of Welfare Stigma", American Economic Review, 73 \#5, December 1983, 1023-1035.

Moulton, Brent. "Random Group Effects and the Precision of Regression Estimates," Journal of Econometrics, 32 \#3 (August, 1986) 385-397. 
National Governor's Association. "Maternal and Child Health Updates", Washington D.C., various issues.

National Governor's Association. "Promising Practices to Improve Results for Young Children", Washington D.C., August 30, 1997.

Rosenzweig, Mark and T. Paul Schultz. "The Behavior of Mothers as Inputs to Child Health: The Determinants of Birth Weight, Gestation, and Rate of Fetal Growth," in Economic Aspects of Health, Victor Fuchs (ed.), University of Chicago Press: Chicago, 1982.

Rosenzweig, Mark and T. Paul Schultz. "Estimating a Household Production Function: Heterogeneity, the Demand for Health Inputs, and Their Effects on Birth Weight," Journal of Political Economy, 91, October $1983,723-746$.

Rosenzweig, Mark and T. Paul Schultz. "The Stability of Household Production Technology, A Replication," The Journal of Human Resources, 23, Fall 1988, 535-549.

Rubin, Alissa. "Poor Children Falling Out of Medicaid's Safety Net," Los Angeles Times, (November 18, 1997) A1.

Saywell, et al. "Hospital and Patient Characteristics of Uncompensated Hospital Care: Policy Implications," Journal of Health Politics, Policy, and Law, 14, 1989, 287-307.

Schwartz, Rachel. "What Price Prematurity," Family Planning Perspectives, 21, July/August 1989, 170-174.

Smith, Roger. "The Timing of Birth," Scientific American, 280 \#3 (March, 1999), 68-75.

U.S. Office of Technology Assessment. Healthy Children: Investing in the Future, OTA-H-344, Washington, D.C.: GPO, 1987a.

Tengs, Tammy O. et al. "Five-Hundred Life-Saving Interventions and Their Cost-Effectiveness", Risk Analysis, 15, June 1995, 369-90.

U.S. Office of Technology Assessment. Neonatal Intensive Care for Low Birthweight Infants: Costs and Effectiveness, OTA-HCS-38, Washington, D.C.: GPO, 1987b.

U.S. General Accounting Office, Health Care Reform: Potential Difficulties in Determining Eligibility for Low Income People, (Washington D.C.: Government Printing Office, July, 1994) document number GAO/HEHS-94

Viscusi, W. Kip. Fatal Tradeoffs: Public and Private Responsibilites for Risk (New YOrk: Oxford University Press) 1992.

Yudkowsky, Beth K., Jennifer Cartland, and Samuel Flint, "Pediatrician Participation in Medicaid: 1978 to 1989," Pediatrics, 85 \#4 (April 1990) 567-577. 